\title{
Ménétrier Disease; 2-Year-Old Boy Presenting With Prolonged Emesis, Generalized Edema and Chance Histopathological Finding of Cytomegalovirus Gastritis: A Case Report
}

\author{
Narry Savage ${ }^{1}$, Emmanuel Siaw ${ }^{2}$, Ashish Patel ${ }^{2}$, Shipra Garg1* \\ ${ }^{1}$ Department of Pediatric Pathology, Phoenix Children's Hospital, Phoenix, AZ \\ ${ }^{2}$ Department of Pediatric Gastroenterology, Phoenix Children's Hospital, Phoenix, AZ \\ *Corresponding author: Shipra Garg, Department of Pediatric Pathology Phoenix Children's Hospital 1919 East Thomas Road \\ Received date: February 18, 2021; Accepted date: April 02, 2021; Published date: April 12, 2021 \\ Citation: Narry Savage, Emmanuel Siaw, Ashish Patel, Shipra Garg (2021) Ménétrier Disease; 2-Year-Old Boy Presenting With Prolonged \\ Emesis, Generalized Edema and Chance Histopathological Finding of Cytomegalovirus Gastritis: A Case Report. J. Archives of Medical Case \\ Reports and Case Study. 4(2); DOI:10.31579/2692-9392/029
}

Copyright: (C) 2021 Shipra Garg, This is an open access article distributed under the Creative Commons Attribution License, which permits unrestricted use, distribution, and reproduction in any medium, provided the original work is properly cited.

\begin{abstract}
Ménétrier disease (MD) is characterized by enlarged gastric folds with associated protein losing gastropathy. In children it is a rare and self-limited cause of protein losing gastropathy. We report a case of a 2-year-old male who presented with prolonged, refractory emesis and peripheral edema. Workup revealed severe hypoalbuminemia, hypoproteinemia, iron deficiency anemia, and high stool alpha-1 antitrypsin. Hepatic protein synthesis was normal with no urinary protein loss. Endoscopy showed antrum sparing, severe erosive gastritis in body and fundus, characteristic of MD. Histologic examination displayed inflammation with eosinophilia, foveolar hyperplasia, atrophic oxyntic epithelium, and rare CMV inclusions. Patient received antiviral therapy, intravenous albumin, diuretic and was discharged on high protein diet. Follow-up revealed clinical recovery, with endoscopy and histology showing normal gastric mucosa throughout the stomach. It is important to remain vigilant of this condition in pediatric population and to include it in the differential diagnosis in cases of protein losing gastroenteropathy.
\end{abstract}

Keywords: ménétrier disease; emesis, hypoproteinemia; cytomegalovirus; hypertrophic gastropathy

\section{INTRODUCTION}

MD is a rare disease typically found in adults, beginning insidiously with epigastric pain, nausea, vomiting, and generalized edema, it gradually becomes increasingly symptomatic with marked protein losing gastropathy [1] MD is considered a premalignant condition in adults being associated with gastric adenocarcinoma, often requiring gastrectomy. [2] In children, MD is rare, presents with identical symptomatology as in adults, but has a starkly different clinical course, as it is a benign, self-limited condition, with mean duration of 5 weeks. [3]

We present a case of a child with protein losing gastropathy associated with chance finding of cytomegalovirus (CMV) inclusions in the gastric body mucosa. This case illustrates the importance of including MD in the differential diagnosis, even in the pediatric population. To date we report the second youngest patient afflicted with this disease reported in literature, the youngest being 5 months younger from South Korea. [4]

\section{CASE REPORT}

A previously healthy 27-month-old boy presented with three-week history of vomiting and lower extremity swelling. He was initially treated by his primary care physician with seven-day course of amoxicillin and ondansetron as needed for vomiting secondary to presumed streptococcal pharyngitis. His symptoms continued despite therapy, and peripheral edema was noted.

Past medical history included full term birth via vaginal delivery to a mother of advanced maternal age. He had regular prenatal and postnatal care, and regularly attended recommended well-child checks. He was fully vaccinated with no known allergies, and no surgical history.

Physical exam revealed an alert, tired, non-ill appearing toddler with generalized edema, most pronounced in bilateral lower extremities. His abdomen was mildly distended, without hepatosplenomegaly or masses. The remainder of the exam was unremarkable. Initial work up revealed marked leukocytosis with lymphocytic predominance, microcytic anemia, marked hypoproteinemia, and marked hypoalbuminemia. Liver function tests were within normal limits indicating normal hepatic synthetic function, and erythrocyte sedimentation rate and C-reactive protein did not indicate active inflammation. Urinalysis was negative for protein, eliminating a renal etiology for hypoproteinemia. Pro-brain natriuretic peptide was within normal limits, ruling out cardiac etiology for edema. Serum quantitative PCR for CMV was positive, with Helicobacter pylori, Epstein-Barr virus, and celiac studies all negative. High level of stool alpha-1 antitrypsin was present. 
Upper endoscopy revealed severe erosive gastritis involving gastric fundus and body, with normal mucosa in the gastric antrum (Figure 1).

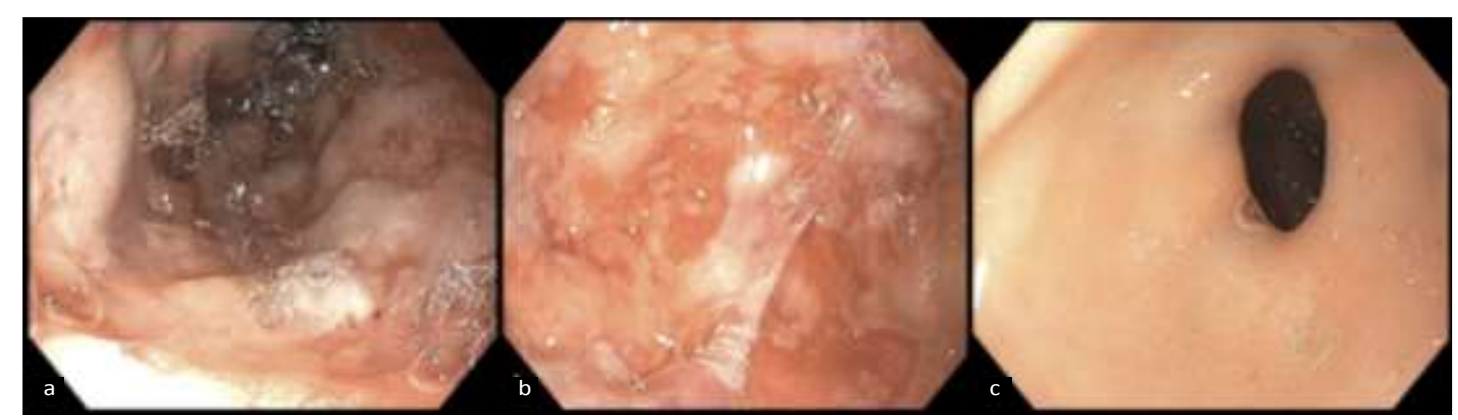

Figure 1: Endoscopic view of markedly thickened gastric folds, with overlying erosions and exudates involving the gastric fundus (a), body (b), and unaffected antrum $(c)$.

Histological evaluation of gastric biopsies of the fundus body revealed mucosal erosion, active inflammation with eosinophilia, edema of the lamina propria, foveolar hyperplasia, cystic dilatation of pits, and atrophy of oxyntic epithelium. Cytomegalovirus inclusions were identified within epithelial cells, verified with immunohistochemical staining (Figures 2a, 2b and 2c). No Helicobacter pylori organisms were seen. No abnormalities were seen histologically in the gastric antrum.

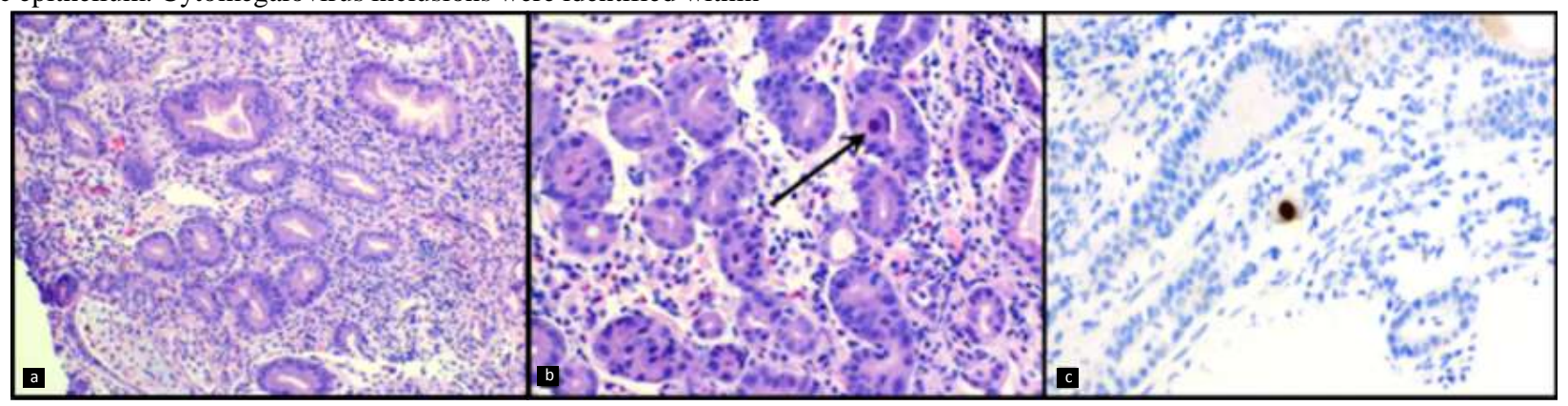

Figure 2: a) Inflamed gastric fundus mucosa showing foveolar hyperplasia and oxyntic epithelial atrophy. H\&E Stain at 100X. magnification b) Inflamed gastric body mucosa with foveolar hyperplasia and focal intranuclear and cytoplasmic CMV inclusion (arrow). H\&E stain at 200X. c) Immunostain for CMV at $200 X$ magnification.

Histological findings of foveolar hyperplasia, oxyntic epithelial atrophy, and CMV inclusions in conjunction with endoscopy findings of gastritis with hypertrophic gastric folds, and clinical findings of peripheral edema, hypoproteinemia, hypoalbuminemia, elevated levels of stool alpha-1 antitrypsin, and positive CMV serology were all consistent with the diagnosis of Ménétrier disease.
Valganciclovir and a proton pump inhibitor therapy were initiated for erosive gastritis, along with albumin infusions and furosemide. Patient was discharged on a high protein diet, and continued antiviral, ferrous sulphate and PPI therapy. On his follow-up visit 4 weeks later, he experienced complete resolution of symptoms. Follow-up gastric endoscopy and histology at 3 months showed normal mucosa throughout, with mild remnant foveolar hyperplasia in gastric body (Figure 3).

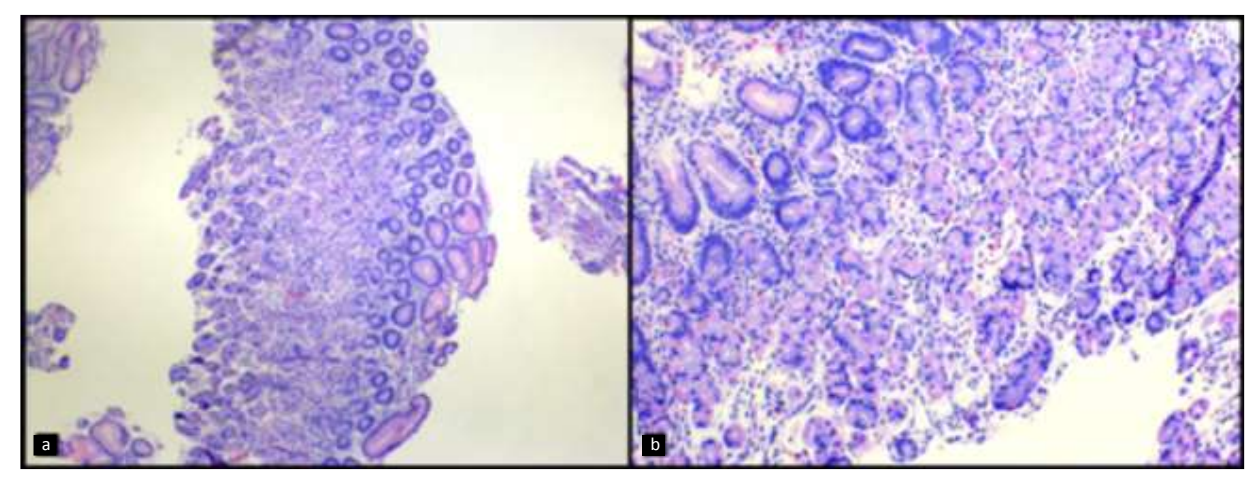




\section{DISCUSSION:}

Pediatric MD is an uncommon, acute, self-limited hyperplastic gastropathy characterized by foveolar hyperplasia and oxyntic epithelial atrophy resulting in protein losing gastropathy [5]. Patients typically present with non-specific symptoms including epigastric pain, nausea, emesis, diarrhea, anorexia, and peripheral edema, sometimes with a history of a viral prodrome. Laboratory studies will reveal hypoalbuminemia, hypochlorhydria, and elevated stool alpha-1antitrypsin level.

Initial imaging with ultrasound can detect hypertrophic rugae, [6] with endoscopic evaluation revealing the enlarged gastric folds of fundus /body and unremarkable antrum. It may be associated with several infectious agents such as CMV, adenovirus, enterovirus, Helicobacter pylori, mycoplasma, herpes virus, and giardia lamblia, [7] with one case documented to be caused by Clostridium difficile. [8]

CMV mediates the changes in the gastric epithelium via increased expression of transforming growth factor alpha (TGF- $\alpha$ ), causing mucus cell proliferation resulting in foveolar hyperplasia. Widened gap junctions between the overabundant foveolar cells permit increased protein leakage from the vasculature into the gastric lumen which is excreted in the stool. [3] This mechanism of protein loss due to CMV is further supported temporally; the resolution of symptoms of hypoproteinemia coincides with the eradication of the infection.

Treatment of Ménétrier disease is directed towards the causative microorganism for gastritis, if one has been identified. Otherwise treatment is symptomatic and supportive in nature. Intravenous albumin can be administered followed by a diuretic such as furosemide to reduce edema and the patient is advised to maintain a high protein, low fat diet. Mean duration of illness is approximately 4-6 weeks.

Besides MD, other clinical conditions that can give rise to protein-losing gastropathy with hypoalbuminemia and subsequent edema include; cardiac failure, malnutrition, impaired hepatic synthesis, excessive renal loss, intestinal lymphangiectasia, or intestinal mucosal inflammation with dysregulated protein permeability.

Diseases showing thickened gastric folds can mimic MD at endoscopy. These conditions range from foveolar hyperplasia in reactive conditions to malignancy. Hypertrophic lymphocytic gastritis shows prominent intraepithelial lymphocytes. Other rare conditions differentiated via histology include Zollinger-Ellison syndrome (characterized by normal foveolar epithelium with parietal cell hyperplasia and hypertrophic hypersecretory gastropathy (hyperplasia of all glandular components) which may or may not be associated with protein loss. Crohn's disease characteristically has gastric granulomas on histology. Peutz-Jeghers syndrome and hyperplastic polyps show foveolar hyperplasia with architectural distortion. Gastric lymphoma and carcinoma are exceedingly rare in children, will display effacement of the mucosa by infiltrating malignant cells Thus endoscopy with histologic correlation should be performed on all suspected cases of gastric mucosal hyperplasia to adequately narrow the differential diagnosis.

In conclusion, our case emphasizes the need to include pediatric Ménétrier disease in the differential diagnosis for a young child with an abrupt onset of vomiting and gastrointestinal protein loss. This case further supports a causal relationship between CMV infection and pediatric Ménétrier disease, highlighting the importance of including this organism as a possible causal agent for this condition.

\section{Conflict of interest: None funding source: None}

\section{References:}

1. Fenoglio-Preiser $\mathrm{CM}$ et al; Hypertrophic hyperplastic gastropathies, In: Gastrointestinal pathology An Atlas and Text; $2^{\text {nd }}$ ed. Philadelphia: Lippincott Raven: 1999: 209-213

2. Almazar AE, Penfield JD, Saito YA, Talley NJ. Survival Times of Patients WithMenetrier's Disease and Risk of Gastric Cancer [published online ahead of print, 2020 Mar 14]. ClinGastroenterolHepatol. 2020;S1542-3565(20)30327-X.

3. Williamson K, Park HK, Schacht R, Kaistha A. A case of Ménétrier disease in a child. PediatrEmerg Care. 2012;28(3):277-279.

4. Hong J, Lee $S$, Shon Y. Ménétrier's disease as a gastrointestinal manifestation of active cytomegalovirus infection in a 22month-old boy: A case report with a review of the literature of korean pediatric cases. ClinEndosc. 2018;51(1):89-94.

5. Garcia V, Cabral M, Carvalho S, Arantes V. Ménétrier disease in a pediatric patient with particular reference to echoendoscopy, endoscopic and anatomopathological presentation and evolutionary therapeutic aspects. J Bras Patol Med Lab. 2017;53

6. Fretzayas A, Moustaki M, Alexopoulou E, Nicolaidou P. Menetrier's disease associated with Helicobacter pylori: three cases with sonographic findings and a literature review. Ann Trop Paediatr. 2011;31(2):141-147.

7. Volonaki E, Haliotis F, van Vliet-Constantinidou C, Avlonitis $\mathrm{S}$, Roma E. Cytomegalovirus infection in a child with menetrier's disease: A case report. Annals of Gastroenterology. 2007;20(3).

8. Zhang J, Wang Y, Liu H, Xiao Y, Zhang T. Ménétrier's disease in childhood: a case report from China. BMC Pediatr. 2020;20(1):110. Published 2020 Mar 6. 
This work is licensed under Creative Commons Attribution 4.0 License

To Submit Your Article Click Here: Submit Article

DOI:10.31579/2692-9392/029
Ready to submit your research? Choose Auctores and benefit from:

* fast, convenient online submission

* rigorous peer review by experienced research in your field

* rapid publication on acceptance

* authors retain copyrights

* unique DOI for all articles

* immediate, unrestricted online access

At Auctores, research is always in progress.

Learn more www.auctoresonline.org/journals/archives-of-medical-casereports-and-case-study 